\title{
Lagrangian water mass tracing from pseudo-Argo, model-derived salinity, tracer and velocity data: An application to Antarctic Intermediate Water in the South Atlantic Ocean
}

\author{
Bruno Blanke $^{\mathrm{a}, *}$, Sabrina Speich ${ }^{\mathrm{b}}$, Emanuela Rusciano ${ }^{\mathrm{a}, \mathrm{b}}$ \\ ${ }^{a}$ Laboratoire de Physique des Océans, UMR 6523 CNRS-Ifremer-IRD-UBO, UFR Sciences et Techniques, 6 avenue Le Gorgeu, CS 93837, 29238 Brest CEDEX 03, France \\ ${ }^{\mathrm{b}}$ Laboratoire de Météorologie Dynamique, UMR 8359 CNRS-École Polytechnique-ENS-UPMC, 24 rue Lhomond, 75231 Paris CEDEX 05, France
}

\section{A R T I C L E I N F O}

\section{Article history:}

Received 5 September 2014

Received in revised form 7 November 2014

Accepted 16 November 2014

Available online 25 November 2014

\section{Keywords:}

Ocean circulation

Conservation equations

Mathematical models

Density field

Subsurface drifters

Intermediate water masses

\begin{abstract}
A B S T R A C T
We use the tracer and velocity fields of a climatological ocean model to investigate the ability of Argo-like data to estimate accurately water mass movements and transformations, in the style of analyses commonly applied to the output of ocean general circulation model. To this end, we introduce an algorithm for the reconstruction of a fully non-divergent three-dimensional velocity field from the simple knowledge of the model vertical density profiles and 1000-m horizontal velocity components. The validation of the technique consists in comparing the resulting pathways for Antarctic Intermediate Water in the South Atlantic Ocean to equivalent reference results based on the full model information available for velocity and tracers. We show that the inclusion of a wind-induced Ekman pumping and of a wellthought-out expression for vertical velocity at the level of the intermediate waters is essential for the reliable reproduction of quantitative Lagrangian analyses. Neglecting the seasonal variability of the velocity and tracer fields is not a significant source of errors, at least well below the permanent thermocline. These results give us confidence in the success of the adaptation of the algorithm to true gridded Argo data for investigating the dynamics of flows in the ocean interior.
\end{abstract}

(c) 2014 Elsevier Ltd. All rights reserved.

\section{Introduction}

Argo data provide invaluable and remarkable information about the ocean structure over the first $2000 \mathrm{~m}$ of the water column, especially in basins that were, until recently, poorly sampled by field experiments (Roemmich et al., 2009). The standard lifestyle of an Argo float is the following: it drifts passively for 8-9 days at depth $1000 \mathrm{~m}$, it dives down to $2000 \mathrm{~m}$ and then samples the water column up to the surface where it can emit data to satellites, before it returns to its parking level. Since the early results proposed by Wong and Johnson (2003), many efforts have been made in using Argo temperature and salinity measurements over the vertical, especially in basins that remained poorly observed until the intensive deployment of Argo floats. Among the recent studies that deal with the South Atlantic (the regional focus of our work) Dong et al. (2011) analysed the performance of a coupled general circulation model with respect to the reproduction of the meridional overturning circulation and meridional heat transport, with and without assimilation of Argo data. Garzoli et al. (2013)

\footnotetext{
* Corresponding author. Tel.: +33298016702.

E-mail address: bruno.blanke@univ-brest.fr (B. Blanke).
}

combined cruise data and Argo profiles to infer the variability these two quantities over 2002-2011. Wu et al. (2011) could relate the spatial distribution of turbulent diapycnal mixing at depths $300-1800 \mathrm{~m}$ to the interaction of the Antarctic Circumpolar Current with the topography by making full use of high-resolution vertical profiles. Sato and Polito (2014) focused on the identification and formation of South Atlantic subtropical mode waters. They showed that most of the eddies sampled by an Argo profile and with marks of these mode waters were anticyclonic.

Probably more marginally because more complicated, some other studies have attempted to make the most of the displacements of autonomous floats at depth, knowing that only the successive positions of the instruments at the sea surface are trackable (e.g., Davis, 2005; Park et al., 2005; Lebedev et al., 2007; Katsumata and Yoshinari, 2010; Menna and Poulain, 2010). In each study, the extrapolation of the start and end of the deep displacement from the successive surface positions is an essential step. Recently, Gray and Riser (2014) used a velocity analysis at the Argo parking depth to produce a reference velocity field for geostrophic calculations at other depths. A few years ago, the Laboratoire de Physique des Océans in Brest (France) undertook a comprehensive processing of the Argo data collected over the 
world ocean to produce an atlas (named ANDRO, for Argo New Displacements Rannou and Ollitrault) of deep displacements based on Argos-tracked surface locations, and fully checked and corrected for possible errors found in the public Argo data files because of wrong decoding or instrumental failure (Ollitrault and Rannou, 2013).

It is tempting to blend absolute velocity information from a dataset like ANDRO and geostrophic velocity profiles obtained over the vertical with the thermal wind equation, as done for instance successfully by Gray and Riser (2014) in their global analysis of the Sverdrup balance. Then, the resulting gridded absolute geostrophic velocity field might be a good candidate for the investigation of water mass displacements and conversions, in the style of the analyses performed on the output of an ocean general circulation models (OGCM), by combining Lagrangian trajectories and the knowledge of in situ temperature and salinity (e.g., Blanke et al., 2006). Unfortunately, the ocean interior is not purely geostrophic, and oceanic variability develops at time scales ranging from a few hours (i.e., internal waves) to several years (i.e., decadal variability) (Ferrari and Wunsch, 2010). Gridded climatologies of temperature and salinity and of the mean absolute geostrophic velocity field correspond to independent calculations, which may result in the poor rendering of the genuine temperature and salinity modifications along three-dimensional movements. The physical reality of the modifications is however essential because they relate to the sudden or progressive conversion of a water mass into another. The study of such water mass transformations refers essentially to the close combination of tracer and velocity information, and a Lagrangian analysis of gridded mass and velocity annual fields may not be so accurate unless special care is brought to the calculations and to the interpretation of the results.

We will not discuss the process of gridding scattered velocity and tracer information though this is of course a crucial step when working with genuine Argo data, and we take the availability of gridded datasets for granted. Our paper aims at testing the successful derivation of a fully non-divergent three-dimensional velocity field by using here, for convenience, synthetic velocity and tracer data calculated and gridded by an OGCM. Our methodology uses only model data that mimic the gridded information that can be retrieved from the profiles and displacements of the Argo profilers. Therefore, we are confident that it will be easily transposable to true, gridded Argo data, while beneficiating from the present results inferred from equivalent and thorough modelbased calculations. For instance, the sensitivity of water mass tracing experiments to the inclusion or exclusion of seasonal variability in the gridded dataset can be investigated in the model, knowing that Argo-derived gridded products consist predominantly of annual mean climatologies that disregard the seasonal scales of ocean variability. Section 2 presents the model simulation that provides pseudo-like Argo information, i.e., the horizontal velocity field at $1000 \mathrm{~m}$ and the vertical profiles of temperature and salinity. Section 3 introduces a retrieval algorithm for the full three-dimensional velocity and tracer fields, and discusses some key hypotheses in the light of known patterns of the circulation of intermediate waters. Section 4 details the validation of the Lagrangian experiments that can be carried out with these fields, with reference to results obtained with the original velocity and tracer model data. Our concluding remarks follow in Section 5.

\section{Model and method}

The numerical simulation we choose for our study is a somewhat realistic description of the world ocean circulation (see detailed description in Blanke et al. (2002)). The model that gener- ated it (the OPA model, Madec et al., 1998) was used mostly as a dynamic interpolator of the mass field derived from an observational climatology of salinity and temperature (Levitus, 1982). The domain simulation extends from $78^{\circ} \mathrm{S}$ to $90^{\circ} \mathrm{N}$ with a $2^{\circ}$ zonal resolution at the equator and a meridional grid interval that varies from $0.5^{\circ}$ at the equator to a maximum of $2^{\circ}$ in the tropics. There are 31 levels in the vertical with the highest resolution $(10 \mathrm{~m})$ in the upper $150 \mathrm{~m}$. The simulation is forced by a daily climatology obtained from the European Centre for Medium-Range Weather Forecasts (ECMWF) 15-year (1979-1993) reanalyses, and smoothed by an 11-day running mean. The restoring term to the Levitus climatology appears as a Newtonian damping in the temperature and salinity equations of the OGCM. The intensity of the restoring is given by the inverse of a characteristic time scale that varies with depth and with the distances from the surface, the coast, and the equator (Madec and Imbard, 1996). The simulation is equilibrated (there is no substantial drift in the tracer and velocity fields after ten years of integration) and the internal sources and sinks of heat and salt introduced by the Newtonian damping balance exactly the surface heat and evaporation-minus-precipitation fluxes that are almost zero when integrated over the global domain. The restoring (together with the climatological atmospheric forcing) is here an essential ingredient to allow useful comparisons with circulation schemes deduced from observations (e.g., Blanke et al., 2001; Friocourt et al., 2005). It does not interact directly with the model turbulent mixing and bottom boundary layer schemes since it is not applied near the coastlines or within the mixed layer. The restoring can still be considered as part of the model physics (at it intends to mimic the effects of poorly performing subgrid scale parameterizations), with a non-local redistribution of heat and salt (unlike lateral and vertical mixing that do conserve heat and salinity through exchanges between adjacent grid cells).

The model horizontal resolution and the time scales kept for variability (monthly averages) compare favourably with the resolution of the gridded atlases one can calculate from in situ Argo data (e.g., Hosoda et al., 2008; Roemmich and Gilson, 2009; von Schuckmann et al., 2009). Of course, at this resolution, the model does not sample the full spectrum of variability of the real ocean: submonthly and subgrid scale movements are only parameterized with physical schemes that account for the mean effect of turbulent lateral and vertical mixing. By comparison, the gridded atlases calculated with Argo data average all the scales of variability truly experienced by the drifters.

One model level for tracers and horizontal velocities lies at $1033 \mathrm{~m}$ and matches appropriately the parking depth of most Argo drifters. Therefore, in this study, we use the annual mean currents modelled at this depth in the South Atlantic Ocean as a reference absolute velocity field. The annual mean values of temperature and salinity are combined to define an average mass field on which the thermal wind equations are applied to derive geostrophic velocity components. The surface wind stress that forced the model is used to estimate the annual mean Ekman circulation that can be added on the total horizontal velocity field. These three stages represent a set of operations that can be applied to true Argo-derived gridded datasets and available wind stress climatologies. The full monthly varying model velocity and tracer fields are kept for reference Lagrangian experiments, to which all comparisons will be made.

The focus is here on the South Atlantic Ocean because the northward spreading of Antarctic Intermediate Water (AAIW) from the Subantarctic Front to the North Atlantic has long been a subject of intense interest (Wüst, 1935; Talley, 1996) and has been addressed in the recent years by major research projects, e.g., GoodHope (Ansorge et al., 2005; Speich and Arhan, 2007) and SAMOC (Garzoli et al., 2007). Our study builds especially on the 
results obtained by Rusciano et al. (2012) on the spreading of AAIW south of Africa, based on a thorough Eulerian analysis of Argo hydrographic profiles and reference displacements at $1000 \mathrm{~m}$. Evidence for AAIW penetration into the South Atlantic north of the Subantarctic Front is a major result of their study, which complements and updates the description of the AAIW circulation in the South Atlantic provided by Suga and Talley (1995). This will be the focus of the model-based water mass tracing experiments developed in Section 4.

\section{Retrieval algorithm for a fully non-divergent 3D velocity field}

On seasonal time scales, the OGCM tracer field is in balance with the velocity field and model physics (which includes here the vertical penetration of the solar radiation, as well as the sources and sinks of tracers induced by the internal restoring of temperature and salinity on climatological values). Water mass tracing requires the knowledge of the three components of the velocity. The vertical velocity is usually several orders of magnitude smaller than the zonal and meridional velocities, but the large-scale volume fluxes are of equivalent magnitude in the three directions because of the depth-to-width aspect ratio of an ocean basin. Volume conservation (no source or sink of volume within the active ocean domain) is a main property to be satisfied, before addressing tracer conservation.

One major difficulty when dealing with absolute geostrophic velocity is the lack of control on $2 \mathrm{D}$ divergence. The implications are huge, since the vertical velocity is mostly a diagnostic field. It can be computed by integrating upward or downward the 2D convergence of the horizontal circulation, noting that it will accumulate all the errors and inaccuracies of the horizontal velocity estimate. Three main issues exist here. First, geostrophy defines horizontal velocity components that are only 2D non-divergent once multiplied by the Coriolis parameter $(f)$; since $f$ varies with the sine of latitude, the deep and open ocean is usually characterized by a balance between the advection of planetary vorticity (the beta effect) and divergence. Second, the absolute velocity field at $1000 \mathrm{~m}$ has no reason for being itself exactly 2D non-divergent; being added at each depth, any local divergence has repercussions on the whole water column and can translate into a linear growth rate (with depth) of the calculated vertical velocity. Finally, the geostrophic relations cannot be applied with confidence near continents or continental slopes where the ocean currents can be highly turbulent or show full three-dimensionality (with for instance topography-induced vertical movements), which adds uncertainty on the vertical velocity.

In this study we propose the following procedure for determining a three-dimensional (3D) velocity field plausibly suitable for trajectory calculations in the ocean interior and eventually for interrelation with tracer or salinity variability. The first guess 3D velocity field consists of the addition of the geostrophic, Ekman and $1000-\mathrm{m}$ absolute components of the horizontal velocity field, as calculated from the annual mean model outputs and forcing fields. Then, a control surface defined at the level of the intermediate waters is used with simple geometric and kinematic considerations to infer the value of vertical velocity at that depth. Finally, a minimization technique finds the optimal barotropic velocity corrections to add to the first guess so that the depth-integrated circulation from the ocean surface to the control surface is compatible with this vertical velocity. The resulting $3 \mathrm{D}$ velocity field will be used as a test bed for Lagrangian experiments: numerical particles will be transported by the zonal, meridional and vertical components of the velocity field across the South Atlantic Ocean, with special insight into water mass modification, in conjunction with the original model tracers.

\subsection{Horizontal interpolation of the model salinity and temperature values}

As already specified, Argo temperature and salinity data are commonly gathered, and possibly merged with other available measurements, to produce gridded fields. The temporal (monthly to annual) and horizontal $\left(0.5^{\circ}\right.$ to $\left.2^{\circ}\right)$ resolution of these Argo-based fields varies according to the period of analysis and to the amount of independent data. For the Southern Ocean, because of more recent systematic deployments of Argo profilers, the definition of robust monthly fields continues to be a challenge. Therefore, the annual mean values of temperature and salinity from the model simulation are good candidates for use as pseudo gridded Argo data.

The equations of the OGCM are discretized on a staggered Cgrid (Arakawa, 1972). The horizontal interpolation of the tracer values onto the " $F$ " points of the grid is a necessary step to calculate easily the horizontal density gradients that provide the zonal and meridional geostrophic components of the flow, on the " $U$ " and "V" points of the C-grid, respectively (Fig. 1). The interpolation is made by averaging the ocean tracer grid points available in the immediate neighbourhood of each "F" grid point. In the absence of any neighbouring tracer information, the " $F$ " grid point remains masked and is considered inland. Then, in the situ density is calculated at the "F" grid points with the formulation that was used in the OGCM (Jackett and McDougall, 1995).

\subsection{Geostrophic velocity components}

At each level of the original model grid, the geostrophic $u_{g}$ and $v_{g}$ components are calculated at the " $\mathrm{U}$ " and " $\mathrm{V}$ " points of the grid with the thermal wind equations, assuming a zero horizontal velocity at $1000 \mathrm{~m}$, or at the ocean bottom if it is locally shallower than $1000 \mathrm{~m}$.

$\left\{\begin{array}{l}\frac{\partial u_{g}}{\partial z}=\frac{g}{\rho_{0} f} \frac{\partial \rho}{\partial y} \\ \frac{\partial v_{g}}{\partial z}=-\frac{g}{\rho_{0} f} \frac{\partial \rho}{\partial x}\end{array}\right.$

The horizontal density gradients are first computed, and then the vertical integration is performed upward.

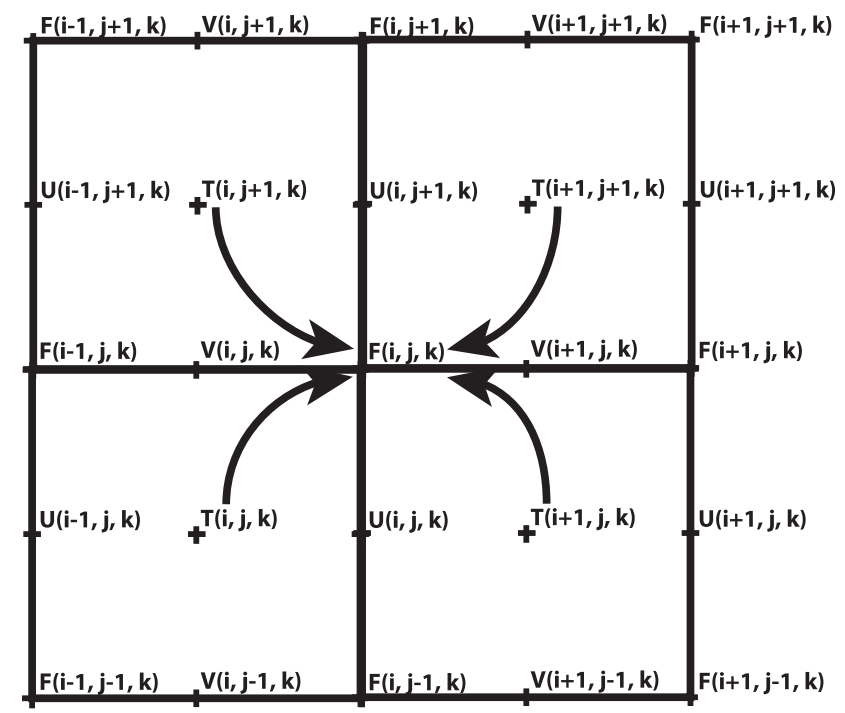

Fig. 1. Horizontal layout of the model variables on a C-grid, at level $k$. Arrows show the horizontal interpolation of the tracer values on the " $F$ " points (first step of the reconstruction algorithm). 


\subsection{Account for a surface wind-induced Ekman spiral}

An analytical Ekman spiral is added from the knowledge on the mean value of the surface wind stress used in the OGCM (a seasonal climatology obtained from the ECMWF reanalyses), with a coefficient of eddy viscosity $\left(A_{v}\right)$ arbitrarily set to a constant:

$u_{e}+i v_{e}=\frac{1}{\rho_{0} \sqrt{2|f| A_{v}}}(1+i)\left(\tau^{\chi}+i \tau^{y}\right) \exp \left\{\sqrt{\frac{|f|}{2 A_{v}}}(1-i) z\right\}$

The formulation was first introduced by Ekman (1905). It is given here in complex variable form and is valid for the Southern Hemisphere $(f<0)$, with $z$ negative and increasing upward $(z=0$ at the sea surface). The actual existence of such a spiral in the real ocean is debatable, especially because the viscosity coefficient actually varies in the vertical (see for instance Ralph and Niiler (1999)), but this is by far the simplest way to account fully for the wind stress forcing in a gridded velocity field. The value of $A_{v}$ is chosen here equal to $10^{-2} \mathrm{~m}^{2} \mathrm{~s}^{-1}$ to match the order of magnitude derived by Chereskin (1995) from the observation with moored instruments of a wind-driven flow in Ekman balance, knowing that the recent results obtained from an underway acoustic Doppler current profiler in Drake Passage suggest eddy coefficients values about 10 times greater (Polton et al., 2013). However, it is worth noting that the value of $A_{v}$ will not interfere much with our Lagrangian calculations since we will focus on movements well below the vertical extent of the theoretical Ekman layer. What matters most is the algebraic divergence of the Ekman transport, which is a function only of the surface wind stress (and of the Coriolis parameter):

$\nabla \cdot\left(U_{e}, V_{e}\right)=-\frac{\nabla \times\left(\tau^{x}, \tau^{y}\right)}{\rho_{0}|f|}$

where, for $H$ much larger than the depth of the surface Ekman layer,

$$
\left\{\begin{array}{l}
U_{e}=\int_{-H}^{0} u_{e} d z=-\frac{\tau^{y}}{\rho_{0}|f|} \\
V_{e}=\int_{-H}^{0} v_{e} d z=\frac{\tau^{x}}{\rho_{0}|f|}
\end{array}\right.
$$

\subsection{Addition of a reference velocity field at $1000 \mathrm{~m}$}

Wherever the ocean floor is deeper than $1000 \mathrm{~m}$, the annual mean reference velocity field $\left(u_{a}, v_{a}\right)$ modelled at $1000 \mathrm{~m}$ is added at each depth. The total velocity fields then reads:

$$
\left\{\begin{array}{l}
u(x, y, z)=u_{g}(x, y, z)+u_{e}(x, y, z)+u_{a}(x, y) \\
v(x, y, z)=v_{g}(x, y, z)+v_{e}(x, y, z)+v_{a}(x, y)
\end{array}\right.
$$

\subsection{Expression of the vertical velocity at intermediate depth}

Most Argo profilers have a parking depth at $1000 \mathrm{~m}$, which strengthens the reliability of the circulation calculated at AAIW depth range. We choose to introduce an additional constraint on the velocity field based on a priori knowledge of the behaviour of this water mass. In this step, we determine on each vertical the depth of minimum salinity, $z_{\mathrm{ctrl}}$, and we estimate the vertical velocity as $w_{\mathrm{ctrl}}=u_{\mathrm{ctrl}} \cdot \nabla z_{\mathrm{ctrl}}$

$\left\{\begin{array}{l}u_{\mathrm{ctrl}}=u_{z=z_{\mathrm{ctrl}}} \\ v_{\mathrm{ctrl}}=v_{z=z_{\mathrm{ctrl}}} \\ w_{\mathrm{ctrl}}=\left(u_{\mathrm{ctrl}}, v_{\mathrm{ctrl}}\right) \cdot \nabla_{z_{\mathrm{ctrl}}}\end{array}\right.$

We suggest here that, in the absence of direct information on vertical velocity, simple geometric consideration can help. In the Southern Ocean, north of the Antarctic Circumpolar Current, the vertical position of the salinity minimum related to AAIW is a useful marker of the 3D velocity field at $\sim 1000 \mathrm{~m}$ depth. Assuming here that turbulent mixing processes have a lesser role than largescale advection in controlling the layout of the temperature and salinity fields, we just ask the 3D movement to operate locally along the chosen control surface:

To broaden the scope of our sensitivity experiments, we also test the assumption of a pure isopycnal flow at the level of the intermediate waters. In this case, the search for the salinity minimum is replaced by the identification of a selected density value on the vertical, $31.77 \sigma_{1}$ to be specific, that is chosen to match optimally the core of the AAIW layer in the South Atlantic domain of the modelled ocean. Alternatively, but less reasonably, the assumption of a horizontal flow at $1000 \mathrm{~m}\left(w_{\mathrm{ctrl}}=0\right)$ can be made to assess the impact on the results of this simplest choice that has been used in recent calculations (Rosell-Fieschi et al., 2013). These three different expressions for $w_{\mathrm{ctrl}}$ will be independently tested in the reconstruction of the 3D non-divergent velocity field.

In the following, $W^{*}$ will denote the corresponding vertical volume flux at depth $z_{\text {ctrl }}$ for each water column of the model grid.

$W^{*}=W_{\text {ctrl }} \Delta x \Delta y$

\subsection{Volume transports}

The optimization of the velocity field calculated with Eq. (5) will consist of making it fully 3D non-divergent and compatible with the vertical velocity field imposed at depth $z_{\text {ctrr. }}$. This will be achieved by making the divergence of the barotropic circulation equal to $W^{*}$. As a preliminary step, we calculate the depth-integrated lateral transport components over the 4 sides of each water column above $z_{\mathrm{ctrl}}(i, j)$ (or above the sea floor if $z_{\mathrm{ctrl}}$ is undefined): $U^{w}(i, j), U^{e}(i, j), V^{s}(i, j)$ and $V^{n}(i, j)$, in $\mathrm{m}^{3} \mathrm{~s}^{-1}$. The indices $w, e, s$, and $n$ refer to the western, eastern, southern and northern sides of the column, with areas $A^{w}, A^{e}, A^{s}$ and $A^{n}$, respectively. Note that the cross-sections $A^{e}(i-1, j)$ and $A^{w}(i, j)$ (just as $A^{n}(i, j-1)$ and $\left.A^{S}(i, j)\right)$ may correspond to different surfaces because of the convergence of the grid meridians, or because $z_{\text {ctrl }}$ can be chosen with horizontal variations (Fig. 2).

\subsection{Computation of an optimal barotropic velocity field}

We formulate the velocity field optimization in terms of a constrained minimization problem that we solve with the help of Lagrange multipliers (e.g., Arfken, 1985). We seek the barotropic corrections $u^{\prime}(i, j)$ and $v^{\prime}(i, j)$ that minimize the Lagrange function

$$
\begin{aligned}
L= & \sum_{i, j}\left(u_{i, j}^{\prime}\right)^{2}+\sum_{i, j} q_{i, j}\left(v_{i, j}^{\prime}\right)^{2}+\sum_{i, j} \lambda_{i, j}\left\{\left(U_{i, j}^{e}+u_{i+1, j}^{\prime} A_{i, j}^{e}\right)\right. \\
& \left.-\left(U_{i, j}^{w}+u_{i, j}^{\prime} A_{i, j}^{w}\right)+\left(V_{i, j}^{n}+v_{i, j+1}^{\prime} A_{i, j}^{n}\right)-\left(V_{i, j}^{s}+v_{i, j}^{\prime} A_{i, j}^{s}\right)-W_{i, j}^{*}\right\}
\end{aligned}
$$

where the weights $p(i, j)$ and $q(i, j)$ that appear in the cost function (i.e., the first two terms of the right-hand side of Eq. (8) will be discussed below. Null partial derivatives of $L$ with respect to each Lagrange multiplier, $\lambda(i, j)$, correspond to the local satisfaction of volume conservation (over the water columns into consideration). The number of such equations is the number of ocean columns used for optimization, $N_{\lambda}$, and each equation reads:

$$
\begin{gathered}
u_{i+1, j}^{\prime} A_{i, j}^{e}-u_{i, j}^{\prime} A_{i, j}^{w}+v_{i, j+1}^{\prime} A_{i, j}^{n}-v_{i, j}^{\prime} A_{i, j}^{s} \\
=W_{i, j}^{*}-\left(U_{i, j}^{e}-U_{i, j}^{w}+V_{i, j}^{n}-V_{i, j}^{s}\right)
\end{gathered}
$$

Null partial derivatives of $L$ with respect to each velocity correction give $N$ relationships between the Lagrange multipliers $\lambda(i, j)$ and $u^{\prime}$ and $v^{\prime}$, such as:

$2 p_{i, j} u_{i, j}^{\prime}-\lambda_{i, j} A_{i, j}^{w}+\lambda_{i-1, j} A_{i-1, j}^{e}=0$ 


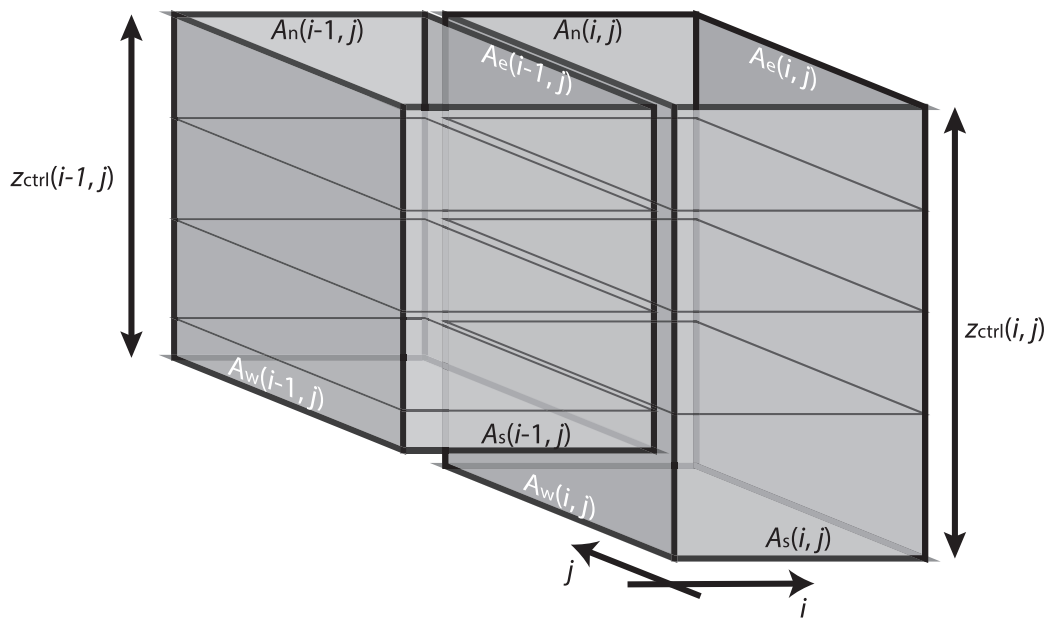

Fig. 2. Example of adjacent water columns over which the volume budget optimization is to be done.

where $N$ is the total number of velocity components to be optimized $\left(N=N_{u}+N_{v}\right)$. Therefore, we can write:

$$
\left[\begin{array}{c}
u_{i, j}^{\prime} \\
v_{i, j}^{\prime}
\end{array}\right]_{N_{u}+N_{v}}^{1}=\left[\mathbf{T}_{N_{u}+N_{v}}^{N_{\lambda}}\left[\lambda_{i, j}\right]_{N_{\lambda}}^{1}\right.
$$

where $T$ represents the transfer matrix defined with Eq. (10), and where the superscript and subscript numbers to the right of the bracketed matrices refer to the numbers of their columns and lines, respectively.

In this minimization algorithm, we aim to diagnose barotropic velocity corrections that are applied over the full extent of the 4 sides of each water column. Null corrections would imply that the volume convergence calculated by default (i.e., with the first guess velocity) already balances the vertical volume flux $W^{*}$ imposed at depth $z_{\mathrm{ctrl}}$. The adjustment of the barotropic velocity comes down to the modification of the reference velocity used for the calculation of the absolute geostrophic velocity. In the case of the ocean model we analyse, this reference field is the simulated annual mean circulation at $1000 \mathrm{~m}$. Its modification is required because this field is not fully consistent with the total - absolute geostrophic and Ekman - circulation we calculated from the model fields, whereas it is fully consistent, of course, with the original mean model circulation. For an application to Argo data, the adjustment of the barotropic velocity would also account for uncertainty in the gridded reference velocity field provided at $1000 \mathrm{~m}$ (Ollitrault and Rannou, 2013). The irregular time sampling of the gridded oceanic domain by the profilers can also bias the estimate of the local annual mean.

Replacing in Eq. (9) each occurrence of $u^{\prime}$ and $v$ by its expression according to the Lagrange multipliers gives a linear system of dimension $N_{\lambda} \times N_{\lambda}$ that can be solved explicitly for the values of the multipliers. Its expression in matrix form is:

$$
[\mathbf{M}]_{N_{\lambda}}^{N_{\lambda}}\left[\lambda_{i, j}\right]_{N_{\lambda}}^{1}=\left[W_{i, j}^{*}-\left(U_{i, j}^{e}-U_{i, j}^{w}+V_{i, j}^{n}-V_{i, j}^{s}\right)\right]_{N_{\lambda}}^{1}
$$

The weights $p(i, j)$ and $q(i, j)$ introduced in Eq. (8) must be chosen carefully. In our case, one can give a weight that depends on the confidence put in each velocity component. Near the coast, because of instability in boundary currents, the first guess calculations give plausibly a poor description of the real circulation, so we use a low weight value. Conversely, in the open ocean, there is less reason to question the validity of the first guess and the weights are chosen larger. As a simple rule, we relate here the local values of $p$ and $q$ to the number $n_{t}$ of tracer profiles truly available in an immediate 6-point-wide neighbourhood of the reference velocity grid point (see example in Fig. 3 ). We use $q=2\left(n_{t}-2\right)$, and the same relationship for $p$. This choice accounts for the interpolation of the original temperature and salinity values on the " $F$ " grid points of the C-grid and for the centred numerical scheme used to derive geostrophic velocity components. It associates small weights to velocity grid points close to the coast. In the open ocean (where 6 independent tracer profiles are available for the horizontal interpolation of temperature and salinity, at grid points $\mathrm{F}(i-1, j)$ and $\mathrm{F}(i, j)$ when dealing with meridional velocity), the weights are maximum and equal to 8. Along a straight coastline, only 4 tracer profiles can be used for the interpolation (with for instance all of them for grid point $\mathrm{F}(i, j)$ and 2 of them for grid point $\mathrm{F}(i+1, j))$, and the weight is equal to 4 . It falls down to zero in the hypothetical case of a narrow channel edged by two coastlines, where the same pair of tracer grid points is used for the interpolation of temperature and salinity at grid points $\mathrm{F}(i-1, j)$ and $\mathrm{F}(i, j)$.

\subsection{Numerical implementation and sample results}

In summary, the numerical implementation of the algorithm consists principally of the calculation of the first guess total velocity field (Eq. (5)), the choice of a value for $w_{\text {ctrl }}$, the calculation of the Lagrange multipliers (Eq. (12)) with a LU decomposition method (see Press et al. (2002) for its numerical implementation),

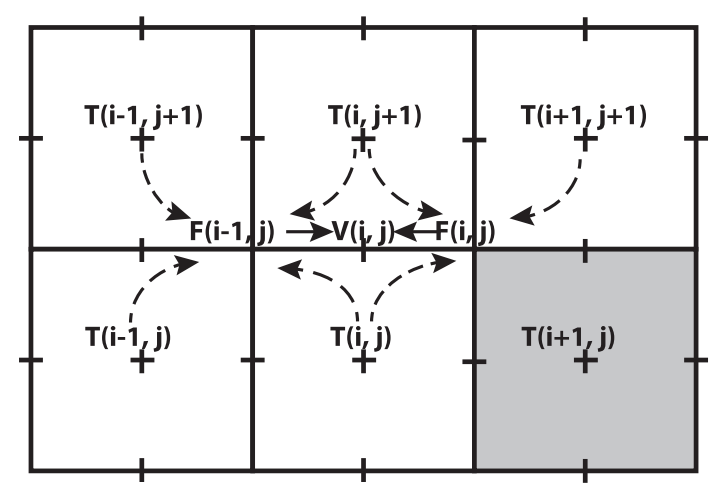

Fig. 3. Example of active neighbourhood for the computation of a meridional velocity value. Dotted arrows show the horizontal interpolation of the tracer values on the " $\mathrm{F}$ " points and solid arrows show the interpolated values used for calculation of the meridional velocity. The shaded tracer grid cell in the bottom right-hand corner is chosen on land and is not used for the interpolation. 
and finally the diagnostic of the barotropic corrections $u^{\prime}$ and $v$ using Eq. (11). The reconstructed fully non-divergent 3D velocity field is obtained by adding these corrections to the total velocity field at each depth. The next section will evaluate the ability of such a reconstructed velocity field to be used in numerical water mass tracing experiments in conjunction with the gridded temperature and salinity fields. The overall performance of the reconstruction will be assessed by a comparison with the reference Lagrangian results derived from the original velocity and tracer model fields (i.e., from the model "truth").

Before that validation stage, it is useful to study the horizontal velocity field at selected depths to better understand the two main steps of the reconstruction. At any depth, the first guess consists of the addition of the geostrophic, Ekman and 1000-m absolute velocity components, noting that the horizontal Ekman circulation is negligible away from the first few hundred meters. Except at $1000 \mathrm{~m}$, where by definition the first guess is equal to the annual mean model velocity field, there are differences between both fields. The top panel of Fig. 4 shows both the original annual mean circulation at $500 \mathrm{~m}$ and the error made by using Eq. (5). As expected, the first guess gives a fair representation of the model truth, especially away from regions of large bathymetric relief (the Walvis ridge, mid-Atlantic ridge and Rio Grande rise, from east to west, to be specific). The relative error made on each horizontal velocity component is rarely above $10 \%$, i.e., a few $\mathrm{mm} \mathrm{s}^{-1}$ at the most. This amplitude is to be compared with the velocity correction calculated by the reconstruction algorithm. We show the latter at $1000 \mathrm{~m}$ (see bottom panel of Fig. 4) because it can be interpreted as an adjustment of the reference velocity field. Since the reconstruction is based on a few adjustable key parameters that are used in combination (the wind stress product used to derive the Ekman circulation; the depth at which an expression is provided for the vertical velocity component; the nature of this expression), the algorithm was in fact applied dozens of times (see Table 1) and we show here only the results obtained with the ECMWF wind and a purely horizontal flow at $1000 \mathrm{~m}$ (Test_5). The barotropic correction calculated by the algorithm is about one order of magnitude smaller than the difference between the estimated and the true annual mean circulation a few hundred meters above (i.e., at $500 \mathrm{~m}$ ). In other words, the adjustment of the first guess (to ensure its full 3D non-divergence and its compatibility with the null vertical velocity field prescribed at $1000 \mathrm{~m}$ ) is smaller than the errors introduced by the construction of the first guess itself. It means that the first guess is close to being compatible with the constraints introduced for the optimization. It also implies that the numerical optimization does not alter dramatically the velocity information readily available from the initial gridded tracer and velocity fields.

\section{Validation protocol}

We test the relevance of the reconstructed velocity field by running Lagrangian analyses in the spirit of diagnoses commonly derived from the output of an OGCM. They aim at diagnosing the volume transfer between a selected set of control sections. In our study, both the intensity of the connection and the evolution of tracers between the sections are checked by comparison with reference calculations done with the original model velocity and tracer fields. One risk of Lagrangian analyses run on independently reconstructed tracer and velocity fields is the diagnosis of invalid salinity or temperature modifications along individual trajectories. An erroneous vertical velocity field, specifically, can introduce significant biases in depth determination and improper interpretation of along-path tracer variations. The care taken here to assess proper constraints on $W$, both at the basis of the surface mixed
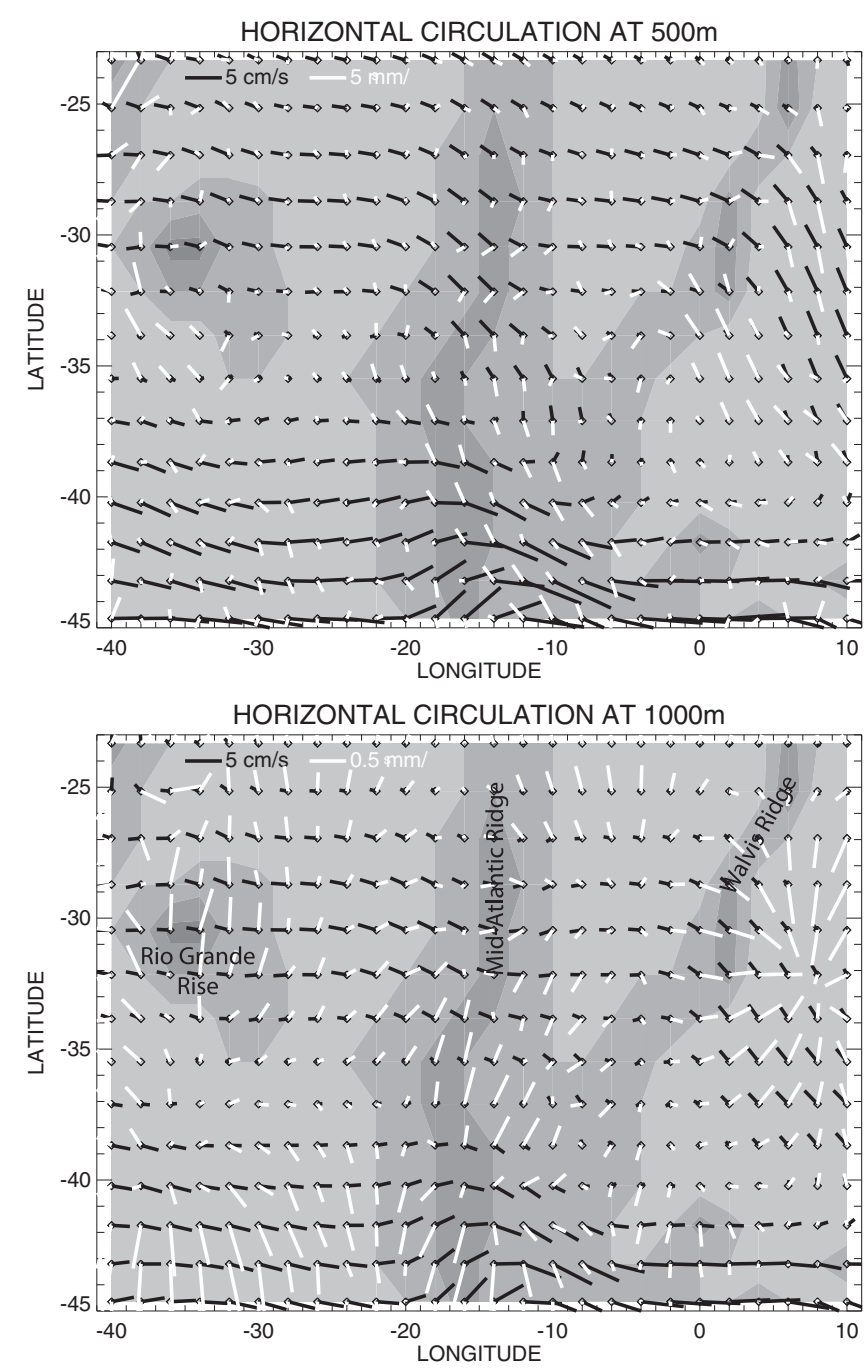

Fig. 4. (top) Original annual mean circulation at $500 \mathrm{~m}$ shown as black segments with a size proportional to the local horizontal velocity. White segments show the difference (magnified 10 times) with the first guest velocity field that consists only of the addition of the geostrophic, Ekman and 1000-m absolute components. (bottom) Original model horizontal circulation at $1000 \mathrm{~m}$ shown as black segments with a size proportional to the local velocity. White segments now show the barotropic correction (magnified 100 times) needed to complete the optimization process and added to the first guess at each level. In both panels, the bathymetry is shaded with a $1000 \mathrm{~m}$ contour interval (the lighter the shading, the deeper the ocean floor) and the bathymetric features mentioned in the text are specified in white in the bottom panel.

layer (Ekman pumping) and at the depth of the intermediate waters, should ensure that this problem is handled correctly in our reconstruction.

Following the work by Rusciano et al. (2012), our analysis is based on the priori knowledge of the fates of the AAIW present southwest of Africa. We diagnose the northward and westward propagation of the low-salinity waters identified at $10^{\circ} \mathrm{E}$ in the depth range $400-1600 \mathrm{~m}$. For this purpose, we use the offline masspreserving Ariane toolkit (http://www.univ-brest.fr/lpo/ariane) (Blanke and Raynaud, 1997; Blanke et al., 1999). The approach allows volume transport estimates based on the tiny weight (here $10^{3} \mathrm{~m}^{3} \mathrm{~s}^{-1}$ ) allotted to each numerical float and transported without alteration along its trajectory. The volume of water transported from an initial to a final geographical section is computed by summing the transport of the numerical floats that achieve the connection that is being considered (Döös, 1995). Default information 
Table 1

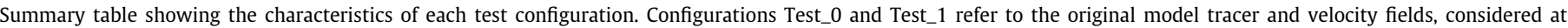
monthly and annual scale, respectively.

\begin{tabular}{|c|c|c|c|c|c|c|}
\hline Experiment name & Origin for the velocity field & Time variability & Wind stress product & Ocean interior constraint on $\mathrm{W}$ & Working depth & $K_{v}\left(\mathrm{~m}^{2} \mathrm{~s}^{-1}\right)$ \\
\hline Test_0 & Model & Monthly & (ECMWF) & $\mathrm{n} / \mathrm{a}$ & $\mathrm{n} / \mathrm{a}$ & $\mathrm{n} / \mathrm{a}$ \\
\hline Test_1 & Model & Annual & (ECMWF) & $\mathrm{n} / \mathrm{a}$ & $\mathrm{n} / \mathrm{a}$ & $\mathrm{n} / \mathrm{a}$ \\
\hline Test_2 & Reconstruction & Annual & ECMWF & $W=0$ & $1000 \mathrm{~m}$ & $\mathrm{n} / \mathrm{a}$ \\
\hline Test_3 & Reconstruction & Annual & ECMWF & $W=0$ & $1800 \mathrm{~m}$ & $\mathrm{n} / \mathrm{a}$ \\
\hline Test_4 & Reconstruction & Annual & ECMWF & Salinity minimum & $\mathrm{n} / \mathrm{a}$ & $\mathrm{n} / \mathrm{a}$ \\
\hline Test_5 & Reconstruction & Annual & ECMWF & Isopycnal flow & $1000 \mathrm{~m}$ & 0 \\
\hline Test_6 & Reconstruction & Annual & ECMWF & Isopycnal flow & $1000 \mathrm{~m}$ & $10^{-5}$ \\
\hline Test_7 & Reconstruction & Annual & ECMWF & Isopycnal flow & $1000 \mathrm{~m}$ & $10^{-4}$ \\
\hline Test_8 & Reconstruction & Annual & ECMWF & Isopycnal flow & $1800 \mathrm{~m}$ & 0 \\
\hline Test_9 & Reconstruction & Annual & ECMWF & Isopycnal flow & $1800 \mathrm{~m}$ & $10^{-5}$ \\
\hline Test_10 & Reconstruction & Annual & ECMWF & Isopycnal flow & $1800 \mathrm{~m}$ & $10^{-4}$ \\
\hline Test_11 & Reconstruction & Annual & $\mathrm{HR}$ & $W=0$ & $1000 \mathrm{~m}$ & $\mathrm{n} / \mathrm{a}$ \\
\hline Test_12 & Reconstruction & Annual & HR & $W=0$ & $1800 \mathrm{~m}$ & $\mathrm{n} / \mathrm{a}$ \\
\hline Test_13 & Reconstruction & Annual & HR & Salinity minimum & $\mathrm{n} / \mathrm{a}$ & $\mathrm{n} / \mathrm{a}$ \\
\hline Test_14 & Reconstruction & Annual & HR & Isopycnal flow & $1000 \mathrm{~m}$ & 0 \\
\hline Test_15 & Reconstruction & Annual & HR & Isopycnal flow & $1000 \mathrm{~m}$ & $10^{-5}$ \\
\hline Test_16 & Reconstruction & Annual & HR & Isopycnal flow & $1000 \mathrm{~m}$ & $10^{-4}$ \\
\hline Test_17 & Reconstruction & Annual & HR & Isopycnal flow & $1800 \mathrm{~m}$ & 0 \\
\hline Test_18 & Reconstruction & Annual & HR & Isopycnal flow & $1800 \mathrm{~m}$ & $10^{-5}$ \\
\hline Test_19 & Reconstruction & Annual & HR & Isopycnal flow & $1800 \mathrm{~m}$ & $10^{-4}$ \\
\hline Test_20 & Reconstruction & Annual & $\tau=0$ & $W=0$ & $1000 \mathrm{~m}$ & $\mathrm{n} / \mathrm{a}$ \\
\hline Test_21 & Reconstruction & Annual & $\tau=0$ & $W=0$ & $1800 \mathrm{~m}$ & $\mathrm{n} / \mathrm{a}$ \\
\hline Test_22 & Reconstruction & Annual & $\tau=0$ & Salinity minimum & $\mathrm{n} / \mathrm{a}$ & $\mathrm{n} / \mathrm{a}$ \\
\hline Test_23 & Reconstruction & Annual & $\tau=0$ & Isopycnal flow & $1000 \mathrm{~m}$ & 0 \\
\hline Test_24 & Reconstruction & Annual & $\tau=0$ & Isopycnal flow & $1000 \mathrm{~m}$ & $10^{-5}$ \\
\hline Test_25 & Reconstruction & Annual & $\tau=0$ & Isopycnal flow & $1000 \mathrm{~m}$ & $10^{-4}$ \\
\hline Test_26 & Reconstruction & Annual & $\tau=0$ & Isopycnal flow & $1800 \mathrm{~m}$ & 0 \\
\hline Test_27 & Reconstruction & Annual & $\tau=0$ & Isopycnal flow & $1800 \mathrm{~m}$ & $10^{-5}$ \\
\hline Test_28 & Reconstruction & Annual & $\tau=0$ & Isopycnal flow & $1800 \mathrm{~m}$ & $10^{-4}$ \\
\hline Test_29 & Reconstruction & Monthly & ECMWF & $W=0$ & $1000 \mathrm{~m}$ & $\mathrm{n} / \mathrm{a}$ \\
\hline
\end{tabular}

interpolated along individual trajectories includes salinity, temperature, depth, and density. The comparison of initial and final statistics for the tracers is, therefore, a good way to assess the reliability of the Lagrangian analysis, knowing that reference results are, in our case, available and robust.

\subsection{Basin-scale experiment with the original model fields}

We use first the full information available from the OGCM to characterize the transmission of intermediate water from south of Africa to the equatorial Atlantic. This step reveals the main pathways to focus on in the South Atlantic Ocean for subsequent sensitivity Lagrangian experiments. In this framework, the lateral control sections are chosen at $21^{\circ} \mathrm{E}$ (south of Africa), $50.7^{\circ} \mathrm{S}$, and $0.25^{\circ} \mathrm{S}$ (just south of the equator). Then, following the results of Reid (1989) and Rusciano et al. (2012), only the depth range from 600 to $1200 \mathrm{~m}$ is seeded at $21^{\circ} \mathrm{E}$ with particles to identify conveniently the AAIW vein.

Initial positions are regularly distributed both in time (still within the same 30 day interval and then repeated for all climatological months) and space (along the vertical and lateral extent of each grid cell). The number of particles in each cell is defined by the constraint about the maximum transport imposed on one single particle (in our case, $10^{-3} \mathrm{~Sv}$ per month; $1 \mathrm{~Sv}=10^{6} \mathrm{~m}^{3} \mathrm{~s}^{-1}$ ). The particles are integrated forward in time until they reach one of the four sections enclosing our South Atlantic domain (see Fig. 5). The resulting connections are portrayed with a Lagrangian horizontal streamfunction, as introduced by Blanke et al. (1999). The AAIW pathways in the model consist mostly of an eastward displacement across the South Atlantic, with a small northward shift, followed by a capture by the western boundary currents and either transmission to the equatorial current system (about 3.9 Sv) or southward recirculation in the subtropical gyre (about $2.9 \mathrm{~Sv}$ ). The organization and intensity of both routes are consistent with the circulation

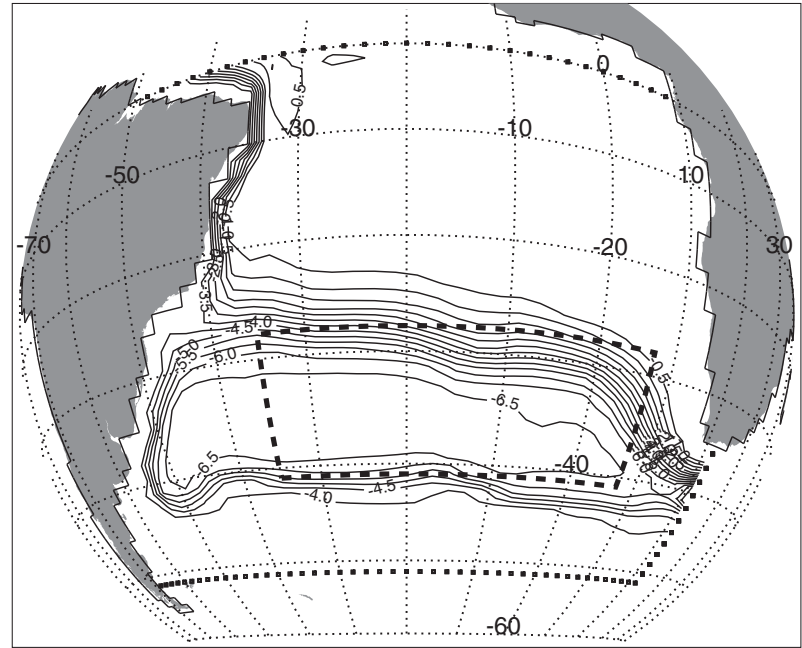

Fig. 5. Lagrangian horizontal streamfunction for the basin-wide experiment. The contour interval is $0.5 \mathrm{~Sv}$. The domain over which the test experiments will be performed is framed with a dashed line.

schemes deduced from observations (e.g., Schott et al., 1995; Núñez-Riboni et al., 2005).

In the rest of the study, we will exclude from our Lagrangian calculations the equatorial domain as well as the oceanic regions too close to continents, where geostrophic calculations and, thus, absolute velocities cannot be trusted. We use the model grid point at $35^{\circ} \mathrm{W}, 27.8^{\circ} \mathrm{S}$ to distinguish conveniently the northward and southward fates of AAIW (see Fig. 5). A zonal interception section at $27.8^{\circ} \mathrm{S}$ and a meridional interception section at $35^{\circ} \mathrm{W}$ define relevant limits for isolating both AAIW branches in the Lagrangian experiments. New limits at $41^{\circ} \mathrm{S}$ and $7^{\circ} \mathrm{E}$ will also be used (see thick dotted lines in Fig. 5). 


\subsection{Framework for the intercomparison of Lagrangian test experiments}

Based on our experience in water mass tracing, we select the following parameters for a quantitative comparison of the results: (i) the volume of water actually transferred from $7^{\circ} \mathrm{E}$ to $35^{\circ} \mathrm{W}$ and $27.8^{\circ} \mathrm{S}$ within both AAIW branches; (ii) the average depth and latitude (longitude) of the transfer mapped at $35^{\circ} \mathrm{W}\left(27.8^{\circ} \mathrm{S}\right)$ and at $7^{\circ} \mathrm{E}$, as well as the associated standard deviations; (iii) the inflowing and outflowing mean temperature and salinity specific to each AAIW branch, again with their standard deviations. The first two sets of parameters refer only to the reconstructed velocity field, whereas the third one combines kinematic and thermodynamic information. We use the full monthly varying tracer and velocity fields of the OGCM to derive reference results (Table 2) against which the Lagrangian experiments run with various reconstructed velocity fields can be compared. The results obtained when using the annual mean model fields are also provided.

The change in the control sections modifies the assessment of the northward transfer (now 5.6 Sv) and westward transfer (now 3.6 Sv) of AAIW (Fig. 6). The analysis is indeed run here over a smaller domain, whereas the first basin-wide experiment was more demanding about the connections to operate: in particular, the volume of water that circulates from $21^{\circ} \mathrm{E}$ to the equator is included in the connection diagnosed from $7^{\circ} \mathrm{E}$ to $27.9^{\circ} \mathrm{S}$, while the reverse is not true. Slightly more than 5 degrees of latitude separate the average positions of both veins at $7^{\circ} \mathrm{E}$, with the westward transfer lying of course south of the northward transfer. The corresponding standard deviations $\left(2.18^{\circ}\right.$ and $\left.1.16^{\circ}\right)$ account for the almost complete separation of the two veins, as shown in Fig. 6. Their depth ranges are similar by construction, but it is worth noting that the northward transfer starts warmer $\left(4.6^{\circ} \mathrm{C}\right)$ and less salty (34.44 psu) than its westward counterpart $\left(3.8^{\circ} \mathrm{C}\right.$ and $34.37 \mathrm{psu}$ ). The geometry of the domain used for Lagrangian integration is such that the spreading at $27.8^{\circ} \mathrm{S}$ is much larger than at $35^{\circ} \mathrm{W}$ (Fig. 6). Between $7^{\circ} \mathrm{E}$ and $27.8^{\circ} \mathrm{S}$, the northward vein is slightly upwelled (about $21 \mathrm{~m}$ in average), warmed $\left(+0.14^{\circ} \mathrm{C}\right.$ ) and freshened $(-0.006 \mathrm{psu})$, whereas the westward vein is downwelled $(-33 \mathrm{~m})$, warmed $\left(+0.3^{\circ} \mathrm{C}\right)$ and salinized $(+0.005)$ from $7^{\circ} \mathrm{E}$ to $25^{\circ} \mathrm{W}$. The standard deviations about the mean values change little between the initial and final states.

For the reconstruction of the velocity field, different Ekman circulations, and thus distributions of Ekman pumping, are tested at the surface to mimic the uncertainty inherent to the surface wind stress climatology that would be selected when dealing with gridded in situ measurements. The standard case uses the same wind stress that was prescribed at the surface of the model during its numerical integration, namely a climatology of momentum fluxes obtained from the ECMWF 15-year (1979-1988) reanalyses. The Hellerman and Rosenstein's (1983) monthly mean climatology is used as an alternative. Another testing case is obtained by omitting the wind stress at the sea surface, i.e., by setting the Ekman circulation to zero. In that case, we simply ignore in the reconstructed velocity field the vertical movements attributable to the convergence or divergence of the wind-induced surface circulation. The vertical velocity on the control surface chosen in the ocean interior is also varied to investigate the dependence of the results on this added assumption: a pure horizontal flow, an isopycnal flow, and a flow along the salinity minimum are successively tested at $1000 \mathrm{~m}$. For an extended analysis, we also shift the constraint deeper in the water column, with the tests of a pure horizontal flow and of a isopycnal flow at $1800 \mathrm{~m}$, within the domain of our Lagrangian calculations. Then, in the case of an isopycnal flow, we test the sensitivity to vertical eddy diffusion in the ocean interior, by rewriting Eq. (6) as an advective-diffusive balance:

$w=\frac{K_{v} \frac{\partial^{2} \rho}{\partial z^{2}}}{\frac{\partial \rho}{\partial z}}+u \frac{\partial z}{\partial x}+v \frac{\partial z}{\partial y}$

where $K_{v}$ is the eddy diffusivity coefficient chosen equal to $0,10^{-5}$, or $10^{-4} \mathrm{~m}^{2} \mathrm{~s}^{-1}$, noting that the non-zero values match or exceed the order of magnitude of published estimates (e.g., Gargett, 1984). The consideration of lateral diffusion would be of course an appreciable extension, but the operator even in its simplest form (horizontal mixing with a Laplacian expression) does not allow for easy inclusion in our optimization algorithm. A total of 30 configurations could be prepared and tested by varying the various options (Table 1).

\subsection{Interpretation of the results}

As a first assessment of the general performance of each reconstructed velocity field, we calculate the sum of the relative errors made on the three sets of parameters previously introduced. Individual relative errors are computed using the "ground truth" (i.e., Lagrangian results obtained with the monthly-varying

Table 2

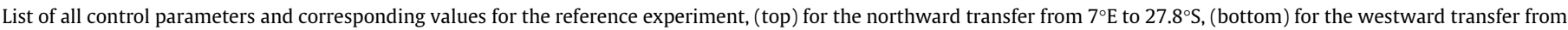
$7^{\circ} \mathrm{E}$ to $35^{\circ} \mathrm{W}$. Means and standard deviations (std) are calculated from the individual properties of the particles that make each connection.

\begin{tabular}{|c|c|c|c|c|c|}
\hline Control parameter & Code & Value & Control parameter & Code & Value \\
\hline Initial section at $7^{\circ} \mathrm{E}$ & & & Final section at $25.8^{\circ} \mathrm{S}$ & & \\
\hline Mean latitude & Yi_n & $32.2^{\circ} \mathrm{S}$ & Mean longitude & Xf_n & $15.7^{\circ} \mathrm{W}$ \\
\hline Latitude std & $\left\langle\mathrm{Yi} \_\mathrm{n}\right\rangle$ & $2.2^{\circ}$ & Longitude std & $\left\langle\mathrm{Xf} \_n\right\rangle$ & $13.9^{\circ}$ \\
\hline Mean depth & $\mathrm{Zi} \_\mathrm{n}$ & $874 \mathrm{~m}$ & Mean depth & Zf_n & $866 \mathrm{~m}$ \\
\hline Depth std & $\left\langle\mathrm{Zi} \_\mathrm{n}\right\rangle$ & $171 \mathrm{~m}$ & Depth std & $\left\langle\mathrm{Zf} \_\mathrm{n}\right\rangle$ & $150 \mathrm{~m}$ \\
\hline Mean temperature & Ti_n & $4.6^{\circ} \mathrm{C}$ & Mean temperature & Tf_n & $4.7^{\circ} \mathrm{C}$ \\
\hline Temperature std & $\left\langle\mathrm{Ti} \_\mathrm{n}\right\rangle$ & $1.1^{\circ} \mathrm{C}$ & Temperature std & $\langle$ Tf_n $\rangle$ & $1.1^{\circ} \mathrm{C}$ \\
\hline Mean salinity & Si_n & 34.44 & Mean salinity & Sf_n & 34.43 \\
\hline Salinity std & $\left\langle\overline{\mathrm{Si}} \_\mathrm{n}\right\rangle$ & 0.05 & Salinity std & $\left\langle\mathrm{Sf} \_\mathrm{n}\right\rangle$ & 0.04 \\
\hline Intensity of the transfer & TR_n & $5.6 \mathrm{~Sv}$ & & & \\
\hline Initial section at $7^{\circ} \mathrm{E}$ & & & Final section at $35^{\circ} \mathrm{W}$ & & \\
\hline Mean latitude & Yi_w & $37.3^{\circ} \mathrm{S}$ & Mean latitude & Yf_w & $29.7^{\circ} \mathrm{S}$ \\
\hline Latitude std & $\left\langle\mathrm{Yi} \_\mathrm{W}\right\rangle$ & $1.2^{\circ}$ & Latitude std & $\left\langle\mathrm{Yf} \_\mathrm{w}\right\rangle$ & $1.2^{\circ}$ \\
\hline Mean depth & Zi_w & $944 \mathrm{~m}$ & Mean depth & Zf_w & $976 \mathrm{~m}$ \\
\hline Depth std & $\left\langle Z Z_{-} \mathbf{w}\right\rangle$ & $166 \mathrm{~m}$ & Depth std & $\langle$ Zf_w $\rangle$ & $136 \mathrm{~m}$ \\
\hline Mean temperature & Ti_w & $3.8^{\circ} \mathrm{C}$ & Mean temperature & Tf_w & $4.1^{\circ} \mathrm{C}$ \\
\hline Temperature std & $\left\langle\overline{T i} \_w\right\rangle$ & $0.8^{\circ} \mathrm{C}$ & Temperature std & $\langle$ Tf_w $\rangle$ & $0.9^{\circ} \mathrm{C}$ \\
\hline Mean salinity & Si_w & $34.37 \mathrm{psu}$ & Mean salinity & Sf_w & $34.38 \mathrm{psu}$ \\
\hline Salinity std & $\left\langle\mathrm{Si} \_\mathrm{w}\right\rangle$ & $0.04 \mathrm{psu}$ & Salinity std & $\langle$ Sf_w $\rangle$ & $0.03 \mathrm{psu}$ \\
\hline Intensity of the transfer & TR_w & $3.6 \mathrm{~Sv}$ & & & \\
\hline
\end{tabular}




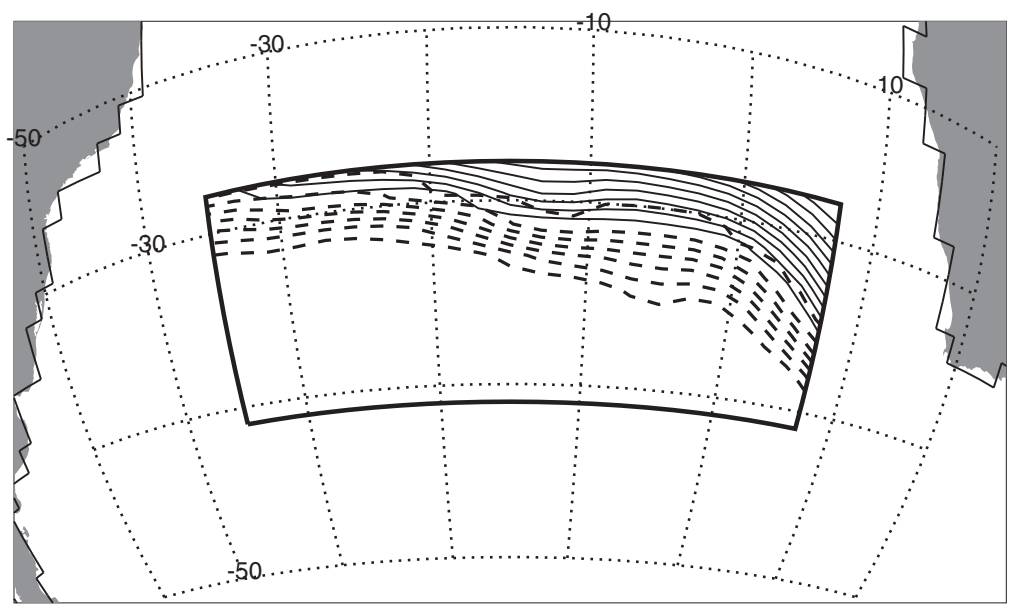

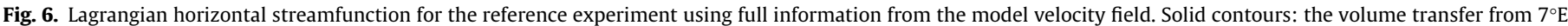
to $27.8^{\circ} \mathrm{S}$. Dashed contours: volume transfer from $7^{\circ} \mathrm{E}$ to $35^{\circ} \mathrm{W}$. The contour interval is $0.5 \mathrm{~Sv}$.

velocity and tracer fields of the model) as a reference. The results are presented in Fig. 7 along two axes to distinguish easily between pure kinematic parameters and parameters that couple tracer and velocity via the Lagrangian analysis.

The main findings from this diagnosis are the following. When working with the original model velocity and tracer fields, only small differences (i.e., a mean relative error of a couple percent) can be noted between the transfers obtained with (Test_0) and without (Test_1) inclusion of seasonal variability. This provides strong confirmation of the ability of annually averaged fields to describe the circulation and water mass conversion in the ocean interior, below the seasonal thermocline. Therefore, the absence of monthly variability in a gridded Argo-derived atlas would not be a critical issue when addressing equivalent matters. Then, the test experiments that assume an isopycnal flow at $1800 \mathrm{~m}$ (tests 8 to 10,17 to 19 and 26 to 28 ) give by far the poorest results, with unacceptable errors on kinematics. The magnitude of the westward transfer to $35^{\circ} \mathrm{W}$ is especially underestimated by more than $40 \%$ in all cases. The main reason for this mismatch is an intense upward velocity that follows from this assumption and that diverts the AAIW from its standard depth range, with dramatic consequences on the shape of the transfer. Finally, the failure to account for the Ekman pumping induced by the surface wind stress (tests 20 to 28) leads to relative errors much higher than those obtained with the inclusion of a surface Ekman spiral, whether it is provided by the genuine atmospheric product that forced the model or by an alternate wind stress climatology. Without Ekman pumping, the reconstruction of the velocity field requires a sizable alteration of

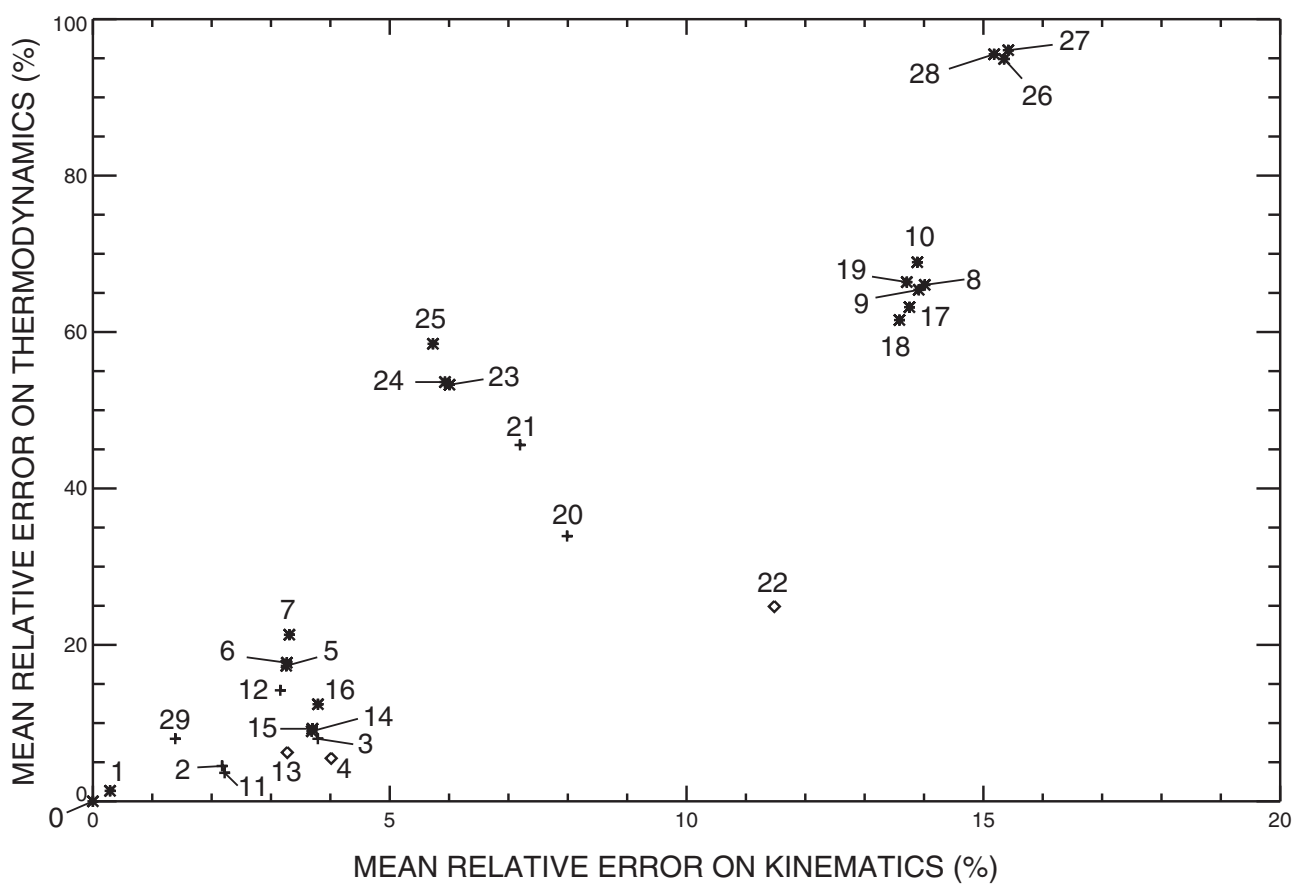

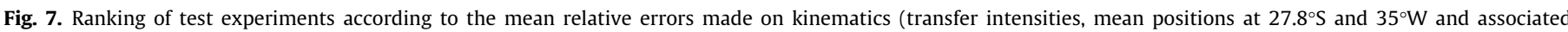

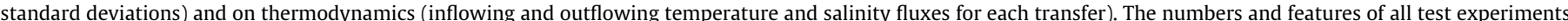

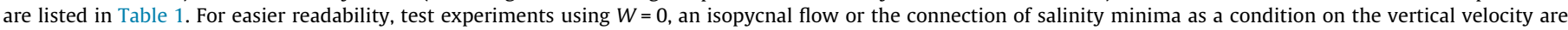
shown with plus, star and diamond symbols, respectively. 
the horizontal velocity field to reconcile the value imposed on vertical velocity at $1000 \mathrm{~m}$ (or, worse, at $1800 \mathrm{~m}$ ) and the nondivergence of the flow.

To emphasize better the main sources of errors in each test experiment, we contour with a log scale the relative errors by taking care to reorder the experiments according to their total score (from the lowest to the highest total error) and to sort the tested parameters according to their general impact on the results (Fig. 8). For instance, the mean initial value of salinity for the two AAIW transfers contribute very little to the total error, whatever the test experiment, and are, therefore, put at the bottom of the diagram. Quite the opposite applies for the standard deviation around the mean salinity values at the end of each transfer. As a result, these two parameters are at the top of the diagram. The test experiments that come out best (Test_2 and Test_11) assume a horizontal flow at $1000 \mathrm{~m}$ and correspond to mean relative errors of the order of $2 \%$ on the kinematic parameters and of the order of $4 \%$ on the thermodynamic parameters. This result is very encouraging because it shows that the bulk of the information on the AAIW circulation is indeed captured by the geostrophic calculations combined with the knowledge of the horizontal circulation at $1000 \mathrm{~m}$ and the quantification of the surface Ekman pumping. More sophisticated constraints such as the prescription of an isopycnal flow at $1000 \mathrm{~m}$ (i.e., a vertical velocity component that, in conjunction with the local horizontal velocity field, leads everywhere at $1000 \mathrm{~m}$ to the alignment of the movement along isopycnal surfaces) or the connection of salinity minima (i.e., 3D movements parallel to the surface encompassing all local salinity minima) do not lead to better results. It is still worth noting that the mean relative errors in these test experiments remain within

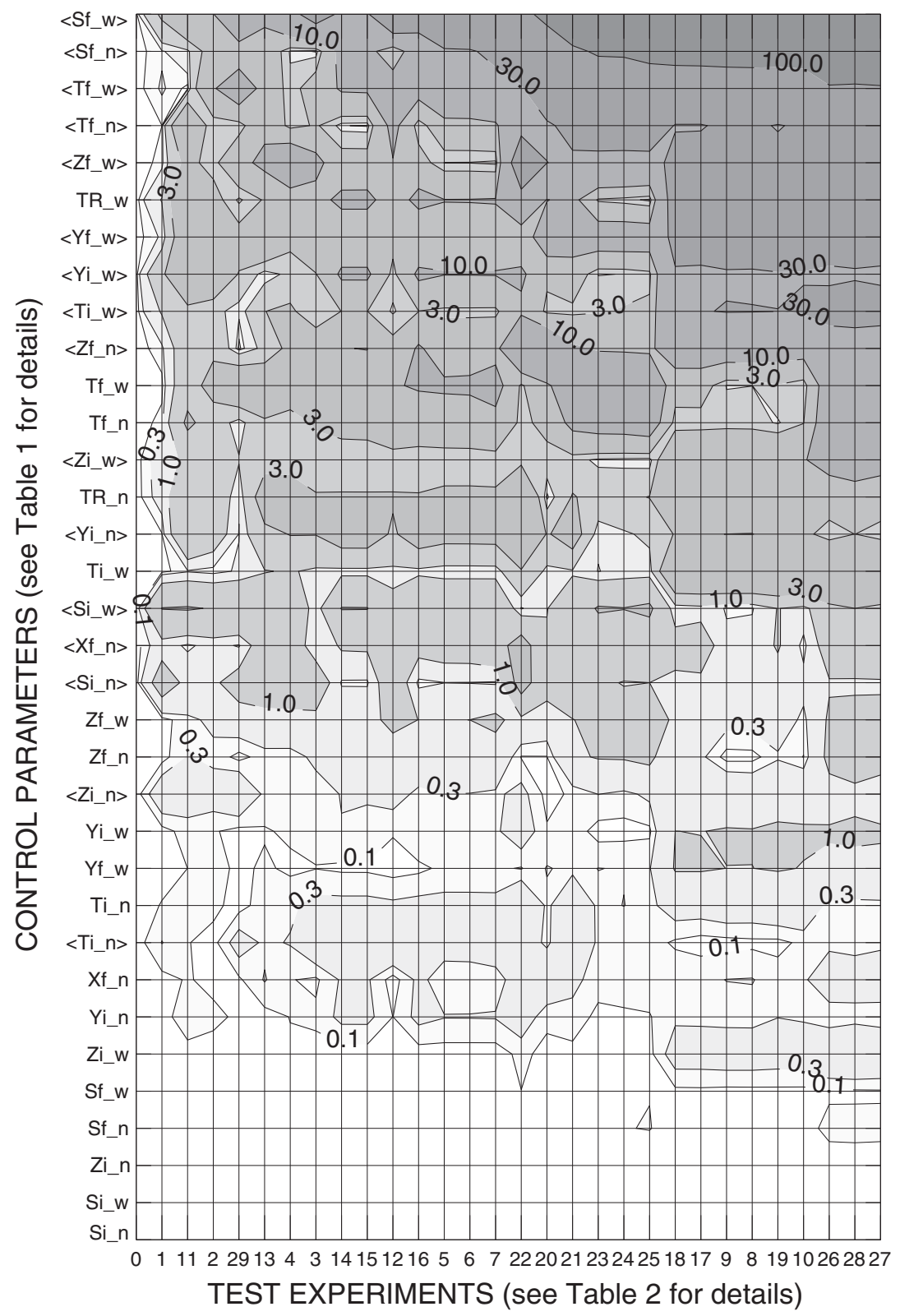

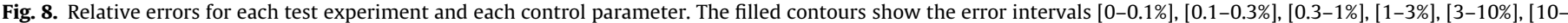

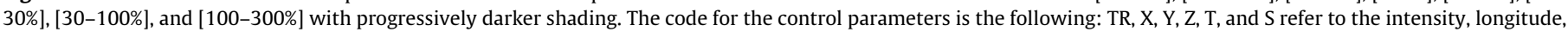

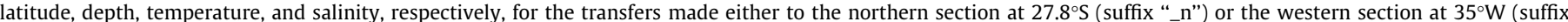

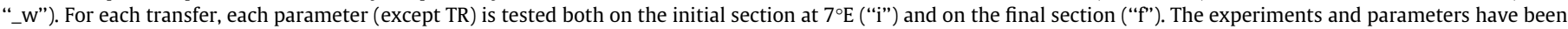
sorted to make the plot more legible (see text for details). 
an acceptable range (of the order of $10 \%$ ). Using the full variable velocity and tracer fields of the OGCM, we could check that the circulation at $1000 \mathrm{~m}$ is not purely isopycnal (even when turbulent vertical mixing is considered), nor does it follow exactly the salinity minimum. Given that the tracer equations in the model include sinks and sources of temperature and salinity through the restoring to the Levitus (1982) seasonal climatology, it is difficult to reach a definitive conclusion as to whether the results with a purely horizontal flow would be always better than the results including more physical considerations, especially when dealing with genuine Argo data. Interestingly, the inclusion of vertical turbulent diffusivity in the diagnostic of the vertical velocity at $1000 \mathrm{~m}$, in the form of an advective-diffusive balance, most often reduces the errors of the test experiments when a realistic value of $10^{-5} \mathrm{~m}^{2} \mathrm{~s}^{-1}$ is used for the eddy diffusivity coefficient (Test_6 and Test_15). Therefore, in the absence of non-local redistribution of heat and salt (i.e., without restoring), turbulent vertical mixing is likely a matter not to be neglected for the derivation of a relevant expression for the vertical velocity.

In the event of promoting monthly gridded datasets for tracer and velocity such as the AGVA (Absolute Geostrophic Velocities from Argo) product distributed by the University of Washington (Gray and Riser, 2014), an optimization of the velocity field based on monthly values is worth testing. This is achieved by defining experiment Test_29 on the basis of the same parameters as Test_2 but with inclusion of monthly variability in the Ekman, geostrophic and reference velocity fields. In the scripts that allow the calculation of the first guess, we simply replace the annual mean values of the model and wind fields by the 12 successive monthly mean climatological values, and the optimization is applied independently over each monthly velocity sample. Unsurprisingly, the reconstructed velocity field shows a good capacity to recover the main features of the AAIW transfers across the South Atlantic. However, the compatibility of the tracer and velocity information is slightly less accurate than for the reconstructions based on annual mean values. We interpret this last result as evidence that the condition used for the vertical velocity at $1000 \mathrm{~m}$ can be acceptable on annual average, but more debatable at monthly scales. This is confirmed by the outcome of another monthly varying test experiment (not shown), using this time the vertical position of the salinity minimum as a marker of the 3D velocity field at $\sim 1000 \mathrm{~m}$ depth (as in Test_4), instead of the less physically grounded zero vertical velocity (as in Test_2). The performance of this experiment in the meaning of the synthesis expressed by Table 1 is comparable to Test_2. It denotes significant improvement over the results of Test_4 run with annual tracer and velocity fields, which validates the use of a physical condition on the vertical velocity in that case.

\section{Concluding remarks}

The reconstruction of the annual average of the 3D velocity field of an OGCM for tracing AAIW in the South Atlantic Ocean, within the spirit of analyses to be done with the climatological information deduced from Argo profilers, has proved successful provided that enough care is brought to the procedure. Accurate surface wind stress information and a suitable expression for the vertical velocity at the level of the intermediate waters are essential ingredients for deriving eventually Lagrangian analyses that do not fall short in comparison with equivalent analyses based on the original model velocity and tracer fields. The emphasis was here on the transmission of AAIW from a meridional section at $7^{\circ} \mathrm{E}$ west of Southern Africa to either the tropical Atlantic $\left(27.8^{\circ} \mathrm{S}\right)$ or to the western boundary current system before southward recirculation (interception at $35^{\circ} \mathrm{W}$ ). The intensity of the transfers as well as the mean and standard deviation of their positioning on each control section were used to assess the soundness of the reconstructed velocity field. The in-depth investigation of the validity of the results also required the careful inspection of the coupling between the velocity and tracer fields, knowing that water mass transformations will likely be well worth studying with gridded Argo data. It was therefore essential to test the thermodynamic properties of the water transferred across the South Atlantic. On that point, our analysis focused on the mean and standard deviation of temperature and salinity at both ends of each transfer. Subtle changes in the vertical velocity that balances the convergence of the horizontal velocity field had major implications for the mapping of initial and final thermodynamical properties, and thus for the inference of the true conversion allowed by turbulent mixing with adjacent water masses. Among the parameters tested in the analysis, the mean initial and final salinity values do not pose significant difficulties. This is quite the reverse for the spreading around these averages, especially on the final interception sections. Unsuccessful test experiments tend to overestimate significantly the standard variation associated with final salinity, a sign that erroneous displacements, either horizontally or vertically, misplaced each AAIW vein or at least altered its identity as a water mass, with too much modification along its displacement.

Successful though it appears in the ocean interior, the reconstruction algorithm is not a relevant technique for an extension of the calculations to regions closer to the continents and to boundary layers. In particular, one cannot rely only on a mathematical optimization algorithm to recover the missing dynamics near the continents where ageostrophic processes can be important. Then, mass conservation on a larger scale would require special care in the definition of an appropriate condition for vertical velocity at all intermediate depths, which may not be straightforward to draft. We guess that a reanalysis of the ocean circulation with the full inclusion of the observations allowed by the Argo network, possibly with a data assimilation scheme, would define a more convenient framework for a study focusing on regions closer to the coast, to the bottom floor or to the surface. Not relying only on Argo and surface wind observations is however a major change in direction that would make obsolete the approach we promote in this study.

Then, it is worth reminding that the OGCM simulation we analyse does not allow eddy-scale variability. At the most, the operators used for lateral and vertical mixing account crudely for some of the turbulence maintained by eddies in the true ocean. Most of the turbulent mixing is actually achieved implicitly, thanks to the restoring applied on tracer values. The restoring terms are especially active in the regions where the model physics cannot account for strong eddy or vertical diffusion and, thus, intend to mimic roughly the physical processes that are missing in the model. Eddy-resolving simulations can provide a more accurate description of the ocean circulation at small scales, but with the disadvantage of not being integrated long enough to describe conveniently the mass exchanges organized at basin scale: several tens (or even hundreds) of years of Lagrangian integrations are needed for instance for a thorough derivation of the mass exchanges analysed in this study. However, these simulations could prove useful to investigate whether tracer-velocity correlations at time scales between a few days and a few months, at the standard parking level of the Argo profilers, do matter for the interpretation of tracer modifications in the longer term.

On-going work targets its application to gridded Argo-derived data, by valuing in particular the deep displacements available in the ANDRO atlas (Ollitrault and Rannou, 2013). The South Atlantic Ocean is a clear target, but we are also looking at investigating the fates and origins of AAIW in other oceanic basins. The extension of the analysis to other water masses merits further research, notably 
to test the relevance of an absolute reference velocity field at $1000 \mathrm{~m}$ for a thorough investigation of displacements at remote depths. Ageostrophic processes and especially turbulent mixing as well as seasonal variability might indeed constitute serious obstacles to the derivation of unbiased Lagrangian analyses. Here again, preliminary tests based on synthetic data, just like those used in this study, could prove highly instructive.

\section{Acknowledgements}

We thank three anonymous reviewers for their valuable contributions that allowed us to improve the manuscript substantially. This research is part of the ANR SAMOC project. Support for this study has also been provided by Centre National de la Recherche Scientifique (CNRS) for BB, by École Normale Supérieure (ENS) for ER and SS, and by Université de Brest (UBO) for ER.

\section{References}

Ansorge, I.J. Speich, S., Lutjeharms, J.R.E., Goni, G.J., de W. Rautenbach, C.J. Froneman, P.W., Rouault, M., Garzoli, S.L., 2005. Monitoring the oceanic flow between Africa and Antarctica: report of the first GoodHope cruise. S. Afr. J. Sci. 101, 29-35.

Arakawa, A., 1972, Design of the UCLA general circulation model. Numerical simulation of weather and climate. Tech. Rep. 7, Dept. of Meteorology, University of California, Los Angeles, $116 \mathrm{pp}$.

Arfken, G., 1985. Mathematical Methods for Physicists, third ed. Academic Press, 985 pp.

Blanke, B., Raynaud, S., 1997. Kinematics of the Pacific Equatorial Undercurrent: an Eulerian and Lagrangian approach from GCM results. J. Phys. Oceanogr. 27, 1038-1053.

Blanke, B., Arhan, M., Madec, G., Roche, S., 1999. Warm water paths in the equatorial Atlantic as diagnosed with a general circulation model. J. Phys. Oceanogr. 29 2753-2768.

Blanke, B., Speich, S., Madec, G., Döös, K., 2001. A global diagnostic of interocean mass transfers. J. Phys. Oceanogr. 31, 1623-1632.

Blanke, B., Speich, S., Madec, G., Maugé, R., 2002. A global diagnostic of interior ocean circulation. Geophys. Res. Lett. 29. http://dx.doi.org/10.1029/ 2001 GL013727.

Blanke, B., Arhan, M., Speich, S., 2006. Salinity changes along the upper limb of the Atlantic thermohaline circulation. Geophys. Res. Lett. 33. http://dx.doi.org/ 10.1029/2005GL024938.

Chereskin, T.E., 1995. Direct evidence of an Ekman balance in the California Current J. Geophys. Res. 100, 18261-18269.

Davis, R.E., 2005. Intermediate-depth circulation of the Indian and South Pacific Oceans measured by autonomous floats. J. Phys. Oceanogr. 35, 683-707.

Dong, S., Baringer, M.O., Goni, G., Garzoli, S.L., 2011. Importance of the assimilation of Argo float measurements on the Meridional Overturning Circulation in the South Atlantic. Geophys. Res. Lett. 38, L18603. http://dx.doi.org/10.1029/ 2011 GL048982.

Döös, K., 1995. Interocean exchange of water masses in the southern ocean. J. Geophys. Res. 100, 13499-13514.

Ekman, V.W., 1905. On the influence of the Earth's rotation on the ocean-currents. Arkiv För Matematik, Astronomi Och Fysik 2, 1-53.

Ferrari, R., Wunsch, C., 2010. The distribution of eddy kinetic and potential energies in the global ocean. Tellus 62A, 92-108.

Friocourt, T., Drijfhout, S., Blanke, B., Speich, S., 2005. Water mass export from Drake Passage to the Atlantic, Indian, and Pacific oceans: a Lagrangian model analysis. J. Phys. Oceanogr. 35, 1206-1222.

Gargett, A.E., 1984. Vertical eddy diffusivity in the ocean interior. J. Mar. Res. 42, 359-393.

Garzoli, S.L., Piola, A., Speich, S., Baringer, M.O., Goni, G., Donohue, K., Meinen, C., Matano, R., 2007. A monitoring system for heat and mass transports in the South Atlantic as a component of the Meridional Overturning Circulation. South Atlantic Meridional Overturning Circulation Workshop Report. <http:// www aoml.noaa.gov/phod/SAMOC/SAMOC report January 08.pdf>.

Garzoli, S.L., Baringer, M.O., Dong, S.F., Perez, R.C., Yao, Q., 2013. South Atlantic meridional fluxes. Deep-Sea Res. Part I-Oceanogr. Res. Papers 71, 21-32. http:// dx.doi.org/10.1016/j.dsr.2012.09.003.

Gray, A.R., Riser, S.C., 2014. A global analysis of Sverdrup balance using absolute geostrophic velocities from Argo. J. Phys. Oceanogr. 44, 1213-1229. http:// dx.doi.org/10.1175/JPO-D-12-0206.1.

Hellerman, S., Rosenstein, M., 1983. Normal monthly wind-stress over the world ocean with error estimates. J. Phys. Oceanogr. 13, 1093-1104.
Hosoda, S., Ohira, T., Nakamura, T., 2008. A monthly mean dataset of global oceanic temperature and salinity derived from Argo flat observations. JAMSTEC Rep. Res. Dev. 8, 47-59.

Jackett, D.R., McDougall, T.J., 1995. Minimal adjustment of hydrographic profiles to achieve static stability. J. Atmos. Oceanic Technol. 12, 381-389.

Katsumata, K., Yoshinari, H., 2010. Uncertainties in global mapping of Argo drift data at the parking level. J. Oceanogr. 66, 553-569. http://dx.doi.org/10.1007/ s10872-010-0046-4.

Lebedev, L., Yoshinari, H., Maximenko, N.A., Hacker, P.W., 2007. YoMaHa'07: velocity data assessed from trajectories of Argo floats at parking level and at the sea surface, IPRC Technical Note No. 4(2), June 12, 16 pp.

Levitus, S., 1982: Climatological Atlas of the World Ocean. NOAA Professional Paper, 13, U.S. Dept. Commerce, Rockville, Md., 173 pp. and 17 microfiches.

Madec, G., Imbard, M., 1996. A global ocean mesh to overcome the North Pole singularity. Clim. Dyn. 12, 381-388.

Madec, G., Delecluse, P., Imbard, M., Lévy, C., 1998. OPA 8.1 ocean general circulation reference manual. Notes du Pôle de Modélisation de l'Institut Pierre-Simon Laplace, 91 pp [Available from LOCEAN, Université Pierre et Marie Curie, Place Jussieu, 75252 Paris Cedex 05, France].

Menna, M., Poulain, P.M., 2010. Mediterranean intermediate circulation estimated from Argo data in 2003-2010. Ocean Sci. 6, 331-343.

Núñez-Riboni, I., Boebel, O., Ollitrault, M., You, Y., Richardson, P., Davis, R., 2005. Lagrangian circulation of Antarctic Intermediate Water in the subtropical South Atlantic. Deep Sea Res. Part II 52, 545-564.

Ollitrault, M., Rannou, J.-P., 2013. An Argo-based deep displacement dataset. J. Atmos. Oceanic Technol, 30, 759-788.

Park, J.J., Kim, K., King, B.A., Riser, S.C., 2005. An advanced method to estimate deep currents from profiling floats. J. Atmos. Oceanic Technol. 22, 1294-1304. http:// dx.doi.org/10.1175/JTECH1748.1.

Polton, J.E., Lenn, Y.-D., Elipot, S., Chereskin, T.K., Sprintall, J., 2013. Can Drake Passage observations match Ekman's classic theory? J. Phys. Oceanogr. 43, 1733-1740. http://dx.doi.org/10.1175/JPO-D-13-034.1.

Press, W.H., Teukolsky, S.A., Vetterling, W.T., Flannery, B.P., 2002. Numerical Recipes in C: The Art of Scientific Computing, second ed. Cambridge University Press, 994 pp.

Ralph, E.A., Niiler, P.P., 1999. Wind-driven currents in the tropical Pacific. J. Phys. Oceanogr. 29, 2121-2129.

Reid, J.L., 1989. On the total geostrophic circulation of the South Atlantic Ocean: Flow patterns, tracers, and transports. Prog. Oceanogr. 23, 149-244. http:// dx.doi.org/10.1016/0079-6611(89)90001-3.

Roemmich, D., Gilson, J., 2009. The 2004-2008 mean and annual cycle of temperature, salinity, and steric height in the global ocean from the Argo Program. Prog. Oceanogr. 82, 81-100. http://dx.doi.org/10.1016/ j.pocean.2009.03.004.

Roemmich, D., Johnson, G.C., Riser, S., Davis, R., Gilson, J., Brechner Owens, W., Garzoli, S.L., Schmid, C., Ignaszewski, M., 2009. The Argo program: observing the global ocean with profiling floats. Oceanography 2, 34-43.

Rosell-Fieschi, M., Rintoul, S.R., Gourrion, J., Pelegrí, J.L., 2013. Tasman Leakage of intermediate waters as inferred from Argo floats. Geophys. Res. Lett. 40, 54565460. http://dx.doi.org/10.1002/2013GL057797.

Rusciano, E., Speich, S., Ollitrault, M., 2012. Interocean exchanges and the spreading of Antarctic Intermediate Water south of Africa. J. Geophys. Res.-Oceans 117. http://dx.doi.org/10.1029/2012JC008266.

Sato, O.T., Polito, P.S., 2014. Observation of South Atlantic subtropical mode waters with Argo profiling float data. J. Geophys. Res.-Oceans 119, 2860-2881. http:// dx.doi.org/10.1002/2013JC009438.

Schott, F.A., Stramma, L., Fisher, J., 1995. The warm water inflow into the western tropical Atlantic boundary regime, spring 1994. J. Geophys. Res. 100, 2474524760.

Speich, S., Arhan, M., 2007. GOODHOPE/Southern Ocean: a study and monitoring of the Indo-Atlantic connections. Mercator Newsletter 27, 29-41.

Suga, T., Talley, L.D., 1995. Antarctic Intermediate Water circulation in the tropical and sub-tropical South Atlantic. J. Geophys. Res. 100, 13441-13453. http:// dx.doi.org/10.1029/95JC00858.

Talley, L.D., 1996. Antarctic Intermediate Water in the South Atlantic. In: Wefer, G., Berger, W.H., Siedler, G., Webb, D.J. (Eds.), The South Atlantic: Present and Past Circulation. Springer Verlag, Berlin Heidelberg, pp. 219-238.

von Schuckmann, K., Gaillard, F., Le Traon, P.-Y., 2009. Global hydrographic variability patterns during 2003-2008. J. Geophys. Res.-Oceans 114, C09007. http://dx.doi.org/10.1029/2008JC005237.

Wong, A.P.S., Johnson, G.C., 2003. South Pacific Eastern subtropical mode water. J. Phys. Oceanogr. 33, 1493-1509.

Wu, L., Jing, Z., Riser, S., 2011. Seasonal and spatial variations of Southern Ocean diapycnal mixing from Argo profiling floats. Nat. Geosci. 4, 363-366. http:// dx.doi.org/10.1038/NGE01156.

Wüst, G., 1935. Schichtung und Zirkulation des Atlantischen Ozeans, Die Stratosphäre. Wissenschaftliche Ergebnisse der Deutschen Atlantischen Expedition auf dem Forschungs- und Vermessungsschiff "Meteor" 19251927. 6: 1st Part. $180 \mathrm{pp}$ (The stratosphere of the Atlantic Ocean, WJ Emery (Ed.), 1978, Amerind, New Delhi, 112 pp). 